\title{
Ion Dynamics Study of Potato Starch + Sodium Salts Electrolyte System
}

\author{
Tuhina Tiwari, ${ }^{1}$ Neelam Srivastava, ${ }^{1}$ and P. C. Srivastava ${ }^{2}$ \\ ${ }^{1}$ Department of Physics (MMV), Banaras Hindu University, Varanasi 221005, India \\ ${ }^{2}$ Department of Physics, Banaras Hindu University, Varanasi 221005, India \\ Correspondence should be addressed to Neelam Srivastava; neelamsrivastava_bhu@yahoo.co.in
}

Received 30 May 2013; Accepted 22 October 2013

Academic Editor: Sheng S. Zhang

Copyright (C) 2013 Tuhina Tiwari et al. This is an open access article distributed under the Creative Commons Attribution License, which permits unrestricted use, distribution, and reproduction in any medium, provided the original work is properly cited.

\begin{abstract}
The effect of different anions, namely, $\mathrm{SCN}^{-}, \mathrm{I}^{-}$, and $\mathrm{ClO}_{4}{ }^{-}$, on the electrical properties of starch-based polymer electrolytes has been studied. Anion size and conductivity are having an inverse trend indicating systems to be predominantly anionic conductor. Impact of anion size and multiplet forming tendency is reflected in number of charge carriers and mobility, respectively. Ion dynamics study reveals the presence of different mechanisms in different frequency ranges. Interestingly, superlinear power law (SLPL) is found to be present at $<5 \mathrm{MHz}$ frequency, which is further confirmed by dielectric data.
\end{abstract}

\section{Introduction}

Potentiality of polymer electrolytes was first recognized by Armand et al. [1]. Since then, extensive work has been carried out in the field resulting in further subdivision of field into different branches, such as gelled polymer electrolyte, polymer-salt complex electrolyte, and composite polymer electrolyte. Biopolymer-based polymer-salt complex electrolytes are relatively new class of material and serving as environment friendly alternates to their synthetic counter parts $[2,3]$. Among the biopolymers-based polymer-salt complexes, starch-based materials are gaining much recognition. Many leading groups [4-8] are working in the field. A review of natural polysaccharides as electroactive polymers by Finkenstadt summarizes the basics and importance of starch-based electrolytes [4]. Conductivity up to $10^{-1.6} \mathrm{~S} / \mathrm{cm}$ is reported by Ning et al. using ionic liquid as a plasticizer in starch-based polymer electrolytes [8].

Most of the reports on the starch-based electrolytes deals only with the electrical properties of system. This motivated us to understand the ion dynamics in these systems. Earlier we have studied potato starch-based electrolyte systems having iodide anion for two different cations $[9,10]$ which exhibited good electrolytic nature. Now, we extended our study to comprehend the effect of different anion in starchbased polymer-salt complexes. $\mathrm{ClO}_{4}{ }^{-}, \mathrm{I}^{-}$, and $\mathrm{SCN}^{-}$anions are known for making polymer-salt complexes with synthetic polymers. Hence, in present paper, we are reporting starchbased electrolyte systems prepared by doping starch with sodium salt of these anions.

Prepared system's electrical behavior is analyzed using Impedance spectroscopy and by representing the impedance data in different formalism, namely, dielectric, modulus and conductivity. The use of conductivity formalism to investigate the dynamics of charge carrier is quite admired because of its simplicity. In 1977, Jonscher proposed "Universal dielectric response" to deal with dielectric properties of materials [11]. Later in 1978 he proposed conductivity power law $\sigma=\sigma_{0}+$ $A \omega^{n}$ [12], which is followed by all kind of disordered materials and hence, termed as "Universal dynamic response" which has been further elaborated by Almond et al. in 1983 [13]. In original work of Jonscher, exponent " $n$ " was restricted to be $<1$ (now known as sublinear power law or Jonscher Power law). With the progress of time it has been recognized that if temperature and frequency range is wider then " $n$ " may also have values $>1$ (known as superlinear power law) [1418]. Though superlinear power law is proposed to exist at very high frequency but in the present system this is found even in $\mathrm{MHz}$ frequency range. Similar behavior is noted by other workers as well [14]. In the present work, a detail investigation is carried out to separate sublinear power law and superlinear power law regions. Number of charge carrier and mobility 
are estimated from dielectric data, to understand the effect of anion size.

\section{Experimental Details}

2.1. Material Preparation. Potato starch (PS) $\left(\mathrm{C}_{6} \mathrm{H}_{10} \mathrm{O}_{5}\right)_{n}$, $\mathrm{NaI}, \mathrm{NaSCN}, \mathrm{NaClO}_{4}$, Glutaraldehyde (GA) $\left(\mathrm{C}_{5} \mathrm{H}_{8} \mathrm{O}_{2}\right)$, and Polyethylene glycol 300 (PEG), all from Loba Chemie, were used to prepare material with distilled water as solvent. Three series of samples (i.e., with three different salts) were prepared using solution cast technique at $30^{\circ} \mathrm{C}$. For $1 \mathrm{gm}$ of starch $\sim 10 \%$ of PEG ( 0.17 gm or 5 drops), sodium salt ( 5 to $50 \%$ of PS), and $2 \mathrm{~mL} \mathrm{GA}$ were taken together in distilled water. Mixtures were stirred at $30^{\circ} \mathrm{C}$ on magnetic stirrer for one hour and heated till it dry. Samples were in film form which was cut in to pieces for study.

2.2. Devices and Technique. AC conductivity is measured by computer controlled HIOKI HiTester LCR meter (3532$50)$ in the range $42 \mathrm{~Hz}$ to $5 \times 10^{6} \mathrm{~Hz}$. Ionic transference number of the material is estimated by dc polarization method using Keithley DMM 2100. Silver foils are used as electrode. Dielectric and Modulus data are estimated from the impedance spectra.

\section{Results and Discussion}

3.1. Transference Number and Electrical Conductivity. The simplest method to establish electrochemical nature is the measurement of ionic transference number $\left(t_{\text {ion }}\right)$. It represents the fractional contribution of ionic charge carrier to the total electrical conductivity. In the present case, this parameter is estimated by dc polarization method [19]. In the procedure, $0.2 \mathrm{~V}$ potential was applied across the $\mathrm{Ag} /$ electrolyte/Ag and current was monitored as a function of time. On the application of voltage, current decreased with time and after some time it became constant as the electrolyte was depleted of charge carrier. $t_{\text {ion }}$ is estimated using following formula:

$$
t_{\text {ion }}=\frac{i_{\text {initial }}-i_{\text {final }}}{i_{\text {initial }}}
$$

where $i_{\text {initial }}$ is the initial current flown and $i_{\text {final }}$ is the value of final saturated current. This $t_{\text {ion }}$ gives the total ionic contribution to conductivity. For all the three systems $t_{\text {ion }}$ has value $\sim 0.99$ which indicates the electrolytic nature of prepared materials. To separate cationic/anionic transference number, combined a.c./d.c. method [20] was used. The method is similar to that described above with the only difference that the blocking electrodes were replaced by nonblocking one. $t_{\text {cation }}$ can be estimated from the cole-cole plot and polarization curve. In the present case, anticipating the movement of both the ions (sodium/iodide) $\mathrm{Na}-\mathrm{Hg}$ amalgam was used as a nonblocking electrode to separate the $t_{\mathrm{Na}+}$. The success was not achieved in present case since water absorbed in the starch matrix started reacting with the amalgam and the experiment failed. But as water is available
TABLE 1: Values of conductivity and dielectric parameters for different salt $\left(\mathrm{NaClO}_{4}, \mathrm{NaI}, \mathrm{NaSCN}\right)$ containing systems along with the salt anion size.

\begin{tabular}{lcccc}
\hline Anion & Size $(\mathrm{pm})$ & $\sigma_{\max }(\mathrm{S} / \mathrm{cm})$ & $\varepsilon^{\prime}$ & $\varepsilon^{\prime \prime}$ \\
\hline $\mathrm{ClO}_{4}{ }^{-}$ & 250 & $7.19 \times 10^{-6}$ & 19.8 & 5.97 \\
$\mathrm{I}^{-}$ & 220 & $1.22 \times 10^{-5}$ & 31.8 & 11.3 \\
$\mathrm{SCN}^{-}$ & 213 & $1.12 \times 10^{-4}$ & 45.2 & 63.5 \\
\hline
\end{tabular}

in starch matrix, the effect of proton and hydroxyl ions on the conductivity of the system cannot be fully ruled out.

Conductivity $(\sigma)$ has been calculated using sample dimension " $L$ " and electrode area " $A$ " with the help of formula

$$
\sigma=\frac{1}{Z^{\prime}} \frac{L}{A}
$$

where $Z^{\prime}$ is intercept on real axis of $Z^{\prime \prime}$ versus $Z^{\prime}$ plots obtained in frequency range $42 \mathrm{~Hz}$ to $5 \mathrm{MHz}$.

In polymer-salt composites, conductivity varies with addition of salt and passes through maxima and minima. Therefore, it indicates that in polymer-salt systems, dissociation of salt and the number of available charge carrier are not directly related to the amount of salt added. Instead, columbic interaction among them together with their interaction with the matrix plays an important role.

Figure 1 shows the conductivity $(\sigma)$ versus $\mathrm{wt} \%$ of salt curves for all the three systems. The variation for all the three systems were following the similar trends as reported for other polymer-salt complex systems. The NaSCN doped system exhibit maximum conductivity $\left(1.12 \times 10^{-4} \mathrm{~S} / \mathrm{cm}\right)$ whereas $\mathrm{NaClO}_{4}$ system exhibited the lowest one $(7.19 \times$ $\left.10^{-6} \mathrm{~S} / \mathrm{cm}\right)$. It indicates that the conductivity is following a trend given as follows:

$$
{\sigma_{\mathrm{SCN}}}^{-}>{\sigma_{\mathrm{I}}}^{-}>\sigma_{\mathrm{ClO}_{4}}^{-}
$$

Table 1 shows anion size and corresponding highest conductivity values of different salt mixed systems. Conductivity is inversely following anion size indicating dominance of anions as charge carriers in the systems.

Systems are further analyzed in terms of number of mobile charge carrier " $N$ " and mobility " $\mu$ ". Conductivity can be represented as

$$
\sigma=N q \mu
$$

where $N$ is number of mobile charge carrier, $q$ is charge on carrier and $\mu$ is the mobility of the system. Mobility of any system can be given as

$$
\mu=\frac{q L^{2}}{4 M \tau_{\mathrm{ep}} k T}
$$

where $q$ is charge on carrier, $L$ is sample thickness, $M$ is defined as the ratio of the sample thickness to twice the Debye length, $\tau_{\text {ep }}$ is relaxation time in presence of polarization [21]. 


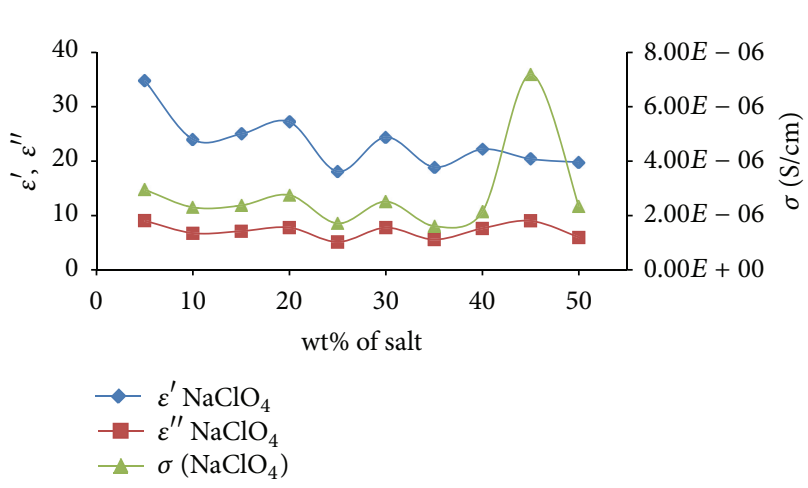

(a)

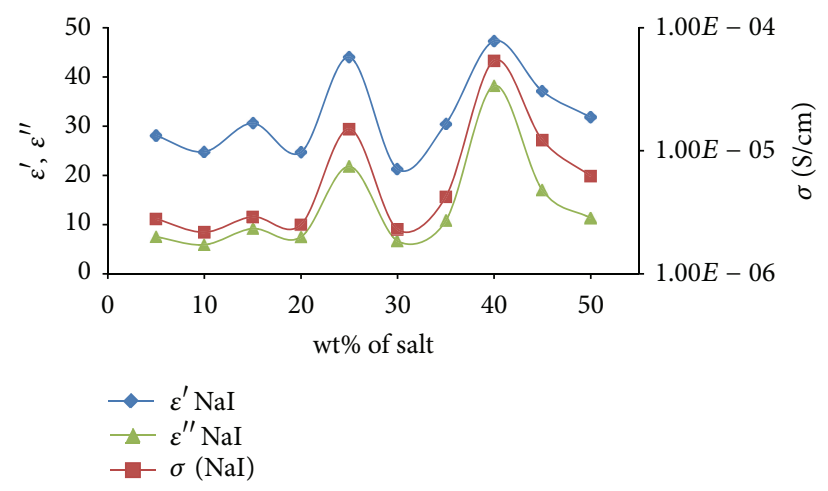

(b)

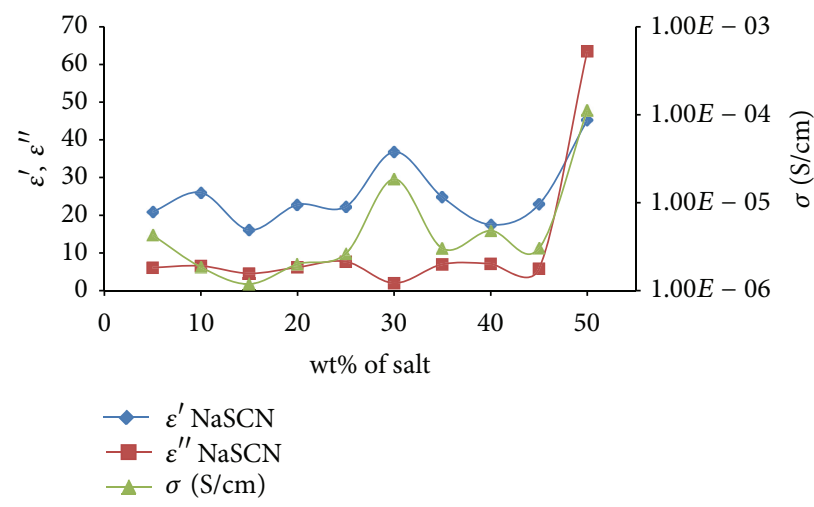

(c)

Figure 1: Variation of conductivity and dielectric parameter with wt $\%$ of added salt (a) $\mathrm{NaClO}_{4}$ Salt, (b) NaI salt, and (c) NaSCN salt.

TABLE 2: Values of $\tau_{\text {ep }}, M, \mu$, and $N$ for different salt $\left(\mathrm{NaClO}_{4}, \mathrm{NaI}\right.$, and $\mathrm{NaSCN}$ ) containing systems.

\begin{tabular}{lcccc}
\hline Salt & $\tau_{\text {ep }}(\mathrm{sec})$ & $M$ & $\mu\left(\mathrm{cm}^{2} \mathrm{~V}^{-1} \mathrm{~s}^{-1}\right)$ & $N\left(\mathrm{~cm}^{-3}\right)$ \\
\hline $\mathrm{NaSCN}$ & $2.43 \times 10^{-4}$ & $3.81 \times 10^{+3}$ & $4.76 \times 10^{-7}$ & $1.47 \times 10^{+21}$ \\
$\mathrm{NaI}$ & $5.17 \times 10^{-3}$ & $9.65 \times 10^{+2}$ & $7.95 \times 10^{-8}$ & $4.89 \times 10^{+20}$ \\
$\mathrm{NaClO}_{4}$ & $2.58 \times 10^{-3}$ & $4.16 \times 10^{+2}$ & $2.12 \times 10^{-7}$ & $6.88 \times 10^{+19}$ \\
\hline
\end{tabular}

$M$ and $\tau_{\text {ep }}$ are correlated with $\tan \delta$ as per following equation:

$$
\tan \delta=\frac{\omega \tau_{\mathrm{ep}}}{1+\omega^{2}\left(\tau_{\mathrm{ep}}^{2} / M\right)}
$$

This formula is best applicable [21] to the systems having conductivity $<10^{-3} \mathrm{~S} / \mathrm{cm}$ and $\tau_{\text {ep }}<1$, thus it can be used in present system. Values of $M, \tau_{\text {ep }}$ can be found by fitting the $\tan \delta$ versus $\omega$ curve for above equation. Fitting parameters are estimated using "Origin" software. Figure 2 shows $\tan \delta$ versus $\omega$ curve for the three systems having $50 \%$ salt. It can be seen that the curve for NaI system has a broad nature. This can be interpreted as distribution in iodide ion's state, that is, indicating the presence of different multiplet of iodide ions, resulting in distributed relaxation time. Iodide ion has a well-known multiplet forming tendency especially in starch; hence, this is an expected behavior.

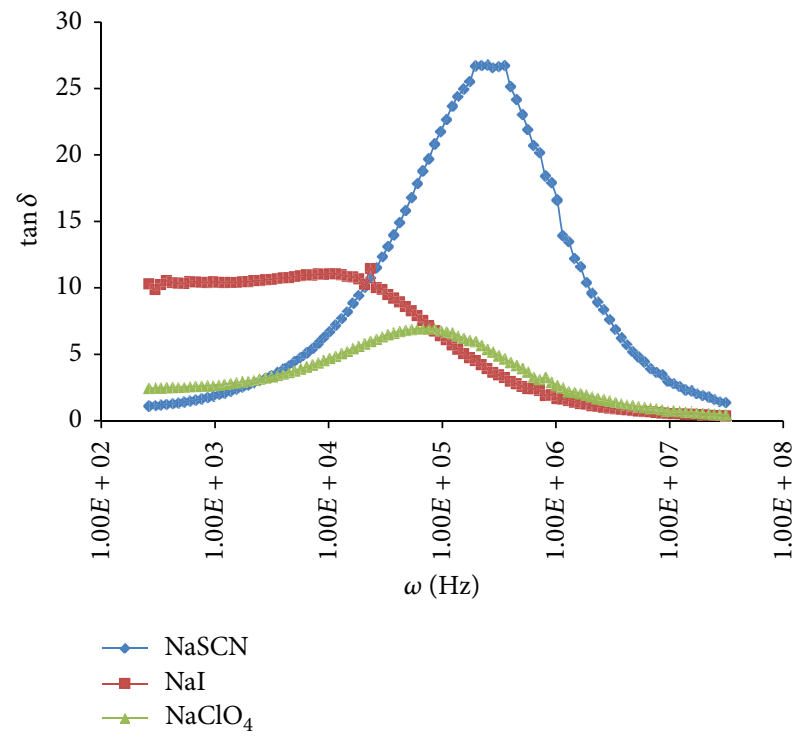

FIgURE 2: $\tan \delta$ versus $\omega$ curve for the three systems (i.e., $\mathrm{NaClO}_{4}$, $\mathrm{NaI}$, and NaSCN containing systems) having $50 \%$ salt.

Table 2 summarizes the values of mobility " $\mu$ " and number of charge carriers " $N$ " for all the three systems having $50 \%$ salt. It indicates that $\mathrm{NaSCN}$ containing system possesses greater $\mu$ and $N$ in comparison to other systems that means 


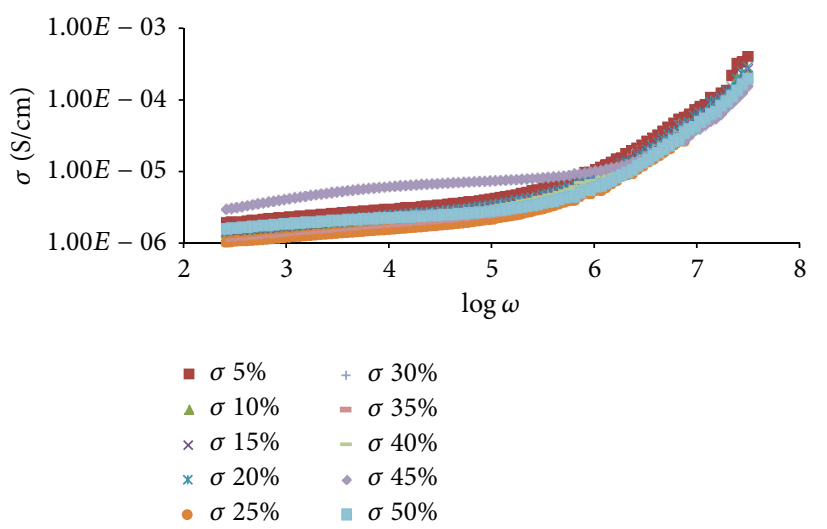

(a)

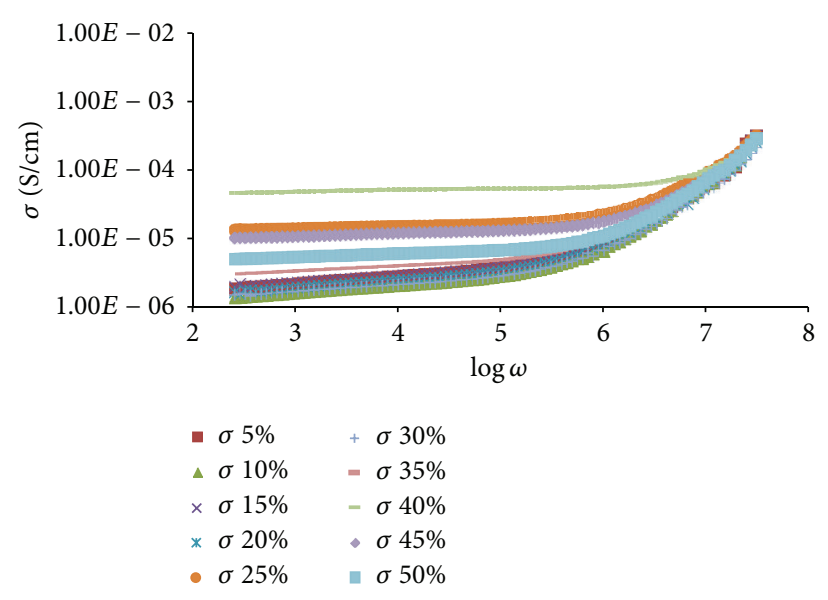

(b)

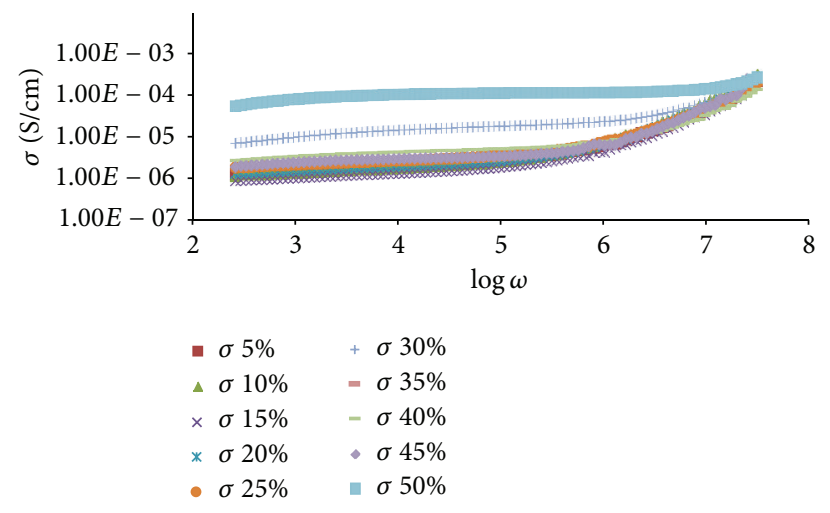

(c)

Figure 3: Conductivity variations with frequency for different system (a) $\mathrm{NaClO}_{4}$ Salt, (b) $\mathrm{NaI}$ salt, and (c) $\mathrm{NaSCN}$ salt.

the anion size not only controls the mobility of the system but at the same time it affects the salt dissociation as well. However, the mobility trend between $\mathrm{NaI}$ and $\mathrm{NaClO}_{4}$ is reversed. Though the single $\mathrm{ClO}_{4}{ }^{-}$ion has greater anion size than the other two ions ( $\mathrm{SCN}^{-}$and $\mathrm{I}^{-}$) hence should have lowest mobility but possibly the greater size of $\mathrm{I}^{-}$multiplet are responsible for reduced mobility in NaI system.

3.2. Frequency Dependence of Conductivity. Impedance data presented in Conductivity formalism $\left(\sigma=\sigma_{0}+A \omega^{n}\right)$ is a well-accepted technique to understand the ion dynamics in disordered systems. The value of exponent " $n$ " represents different types of ion motion dominating in the system [22]. For a very long period, Universal Power Law $[12,13,23]$ has been followed as thumb rule according to which exponent " $n$ " can have values $<1$ and preferably $\simeq 0.5-0.65$ for conducting systems. This law was followed by almost all disordered materials, such as glasses, conducting polymers, and composites [22]. Recently, many experimental data reported in the literature have $n=1$ or $>1$ and are known as Nearly Constant Loss (NCL) and Super Linear Power Law (SLPL), respectively. Though theories predicted these phenomena to occur in $\mathrm{GHz}$ range but experimentally exponent " $n$ " were reported to have $\geq 1$ even in $\mathrm{MHz}$ range [14], theories for explaining such behavior are still in their infancy [14-18, 22]. Exponent depends upon frequency and it designates the ion dynamics prevailing in that frequency range. DC conductivity and ion hopping occur at comparatively larger time scale (low frequency) whereas NCL/SLPL is a lower time scale (higher frequency) phenomena [24], and are represented by $n<$ 1 and $n \geq 1$, respectively. All these are time dependence and hence the ion movements are statistical in nature, with particular phenomenon dominating in specific frequency region and resulting in corresponding value of " $n$ " in that frequency region.

Theoretically, frequency dependence of conductivity will follow a trend $[15,22]$ given below from lower to higher frequency (up to $\mathrm{GHz}$ frequency):

$$
\begin{aligned}
\text { polarization } & \longrightarrow \mathrm{dc} \text { conductivity } \quad(n \sim 0) \\
& \longrightarrow \text { ion hopping } \quad(n \sim 0.5) \\
& \longrightarrow \mathrm{NCL} \quad(n=1) \longrightarrow \mathrm{SLPL} \quad(n>1) .
\end{aligned}
$$

The literature shows that moving beyond the SLPL region, conductivity achieves a plateau followed by dispersion in frequency $>\mathrm{GHz}$ [22], which is not discussed here as it is beyond the scope of present work. When studies have been carried out in wider frequency and temperature range, 


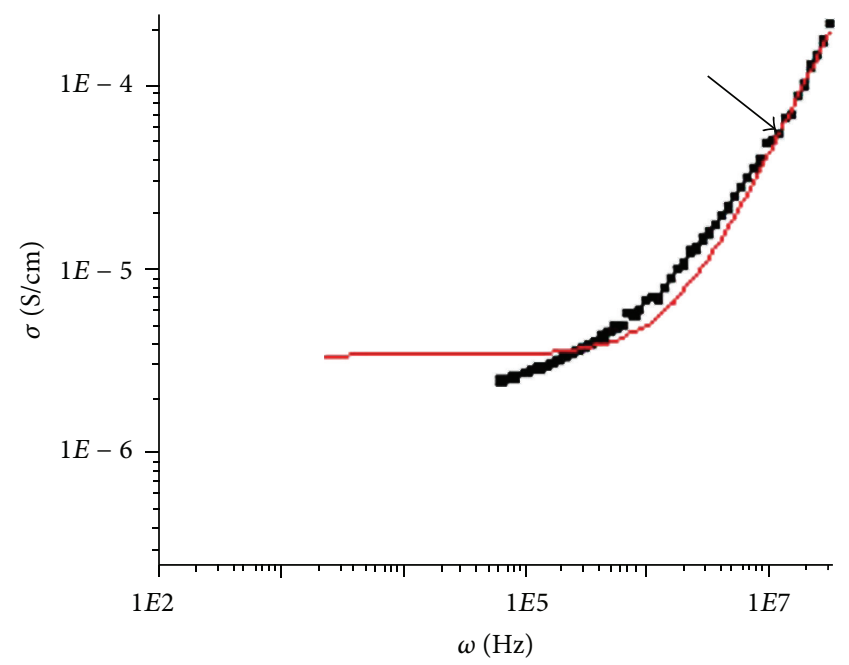

(a)

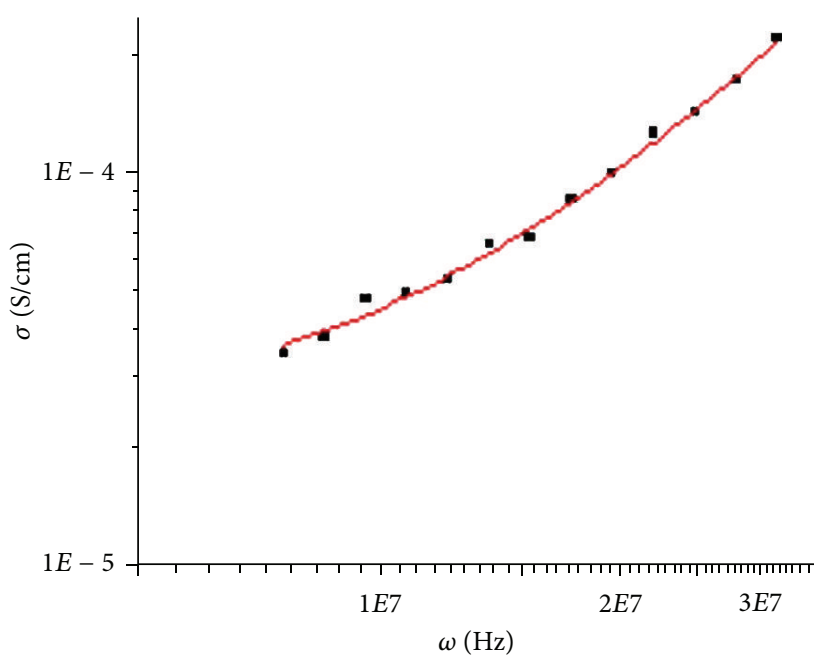

(b)

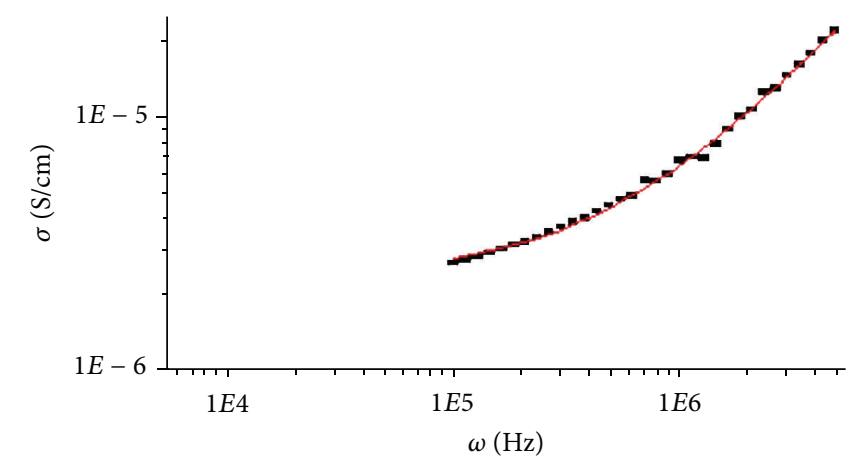

(c)

Figure 4: (a) A typical fitting curve for $\sigma=\sigma_{0}+A \omega^{n}$ along with the experimental points in complete frequency range. (b) Fitting for the same curve in the higher frequency range above the arrow marked in (a). (c) Fitting for the same curve in the lower frequency range below the arrow marked in (a).

universality of $\sigma=\sigma_{0}+A \omega^{n}$ extend to nearly constant loss type of behavior $[14,15,25]$. But SLPL is reported only in few systems. Different theoretical models are being devised to explain NCL/SLPL which are applicable to all material [14-18] but with limited success. In a recent communication, Tiwari and his co-worker [26], referring ADWP model, reported that the NCL/SLPL phenomena can exist even at low frequency decided by glass transition temperature and working temperature together. In the present system, $T_{g}$ is found to be $\sim 80^{\circ} \mathrm{C}$ [27]; hence, according to Tiwari and Shahi [26], at low temperature the power law exponent $(n=$ $1+T / T_{q}$ ) comes out to be $\sim 1.8$ which did not exactly match with experimental values but confirmed the SLPL type phenomenon in present system. A detail discussion of conductivity power law in present system is given below.

Figure 3 shows $\log \sigma$ versus $\log \omega$ curve for present systems. As discussed above, the value of exponent " $n$ " will have different value, varying from 0 to 2 , in different frequency region. As indicated by arrow in Figure 3 the polarization is present up to quite high frequency.

Figure 4(a) shows the fitting curve for $\sigma=\sigma_{0}+A \omega^{n}$ along with the experimental points in complete frequency range, excluding the polarization region. The curve does not exactly fit according to the equation, indicating the existence of different ion dynamics. Curve starts deviating at certain frequency (as marked by arrow in present case), indicating existence of different fitting parameters above and below this frequency. When the fitting was carried out separately in two different frequency ranges, it was quite good as shown in Figures 4(b) and 4(c). This resulted in two sets of fitting parameter in two different regions.

Table 3 shows the values of exponent " $n$ " in different frequency ranges for the three salt systems. We are getting two different regions: higher frequency region with $n>1$ indicating SLPL phenomenon; mid frequency region with $n \simeq 0.5$ representing ion hopping. There are many theoretical attempts [14-18] to provide an explanation to the behavior but none is completely successful.

3.3. Frequency Dependence of Dielectric and Modulus Values. Dielectric parameters estimated at frequency $5 \mathrm{MHz}$ for the three different salts are listed in Table 1 . The anion size effect could also be seen in these data. The values are maximum for $\mathrm{SCN}^{-}$and minimum for $\mathrm{ClO}_{4}{ }^{-}$. The variation of dielectric 
TABLE 3: Values of exponent " $n$ " in different frequencies (Ion hopping and SLPL) range for (a) $\mathrm{NaClO}_{4}$, (b) NaI, and (c) $\mathrm{NaSCN}$ containing systems.

(a) $\mathrm{NaClO}_{4}$

\begin{tabular}{lcc}
\hline wt $\%$ of Salt & \multicolumn{2}{c}{ Value of exponent “ $n$ ” } \\
& $\begin{array}{c}\text { Higher frequency } \\
\text { range }\end{array}$ & $\begin{array}{c}\text { Lower frequency } \\
\text { range }\end{array}$ \\
\hline 5 & 1.77 & 0.53 \\
10 & 1.61 & 0.49 \\
15 & 1.53 & 0.53 \\
20 & 1.51 & 0.51 \\
25 & 1.51 & 0.52 \\
30 & 1.39 & 0.52 \\
35 & 1.47 & 0.47 \\
40 & 1.37 & 0.54 \\
45 & 1.46 & 0.36 \\
50 & 1.39 & 0.51 \\
\hline
\end{tabular}

(b) $\mathrm{NaI}$

\begin{tabular}{lcc}
\hline wt\% of Salt & \multicolumn{2}{c}{ Value of exponent “ $n$ " } \\
& $\begin{array}{c}\text { Higher frequency } \\
\text { range }\end{array}$ & $\begin{array}{c}\text { Lower frequency } \\
\text { range }\end{array}$ \\
\hline 5 & 1.76 & 0.60 \\
10 & 1.68 & 0.68 \\
15 & 1.50 & 0.65 \\
20 & 1.47 & 0.58 \\
25 & 1.31 & 0.62 \\
30 & 1.40 & 0.62 \\
35 & 1.35 & 0.65 \\
40 & 1.50 & 0.41 \\
45 & 1.36 & 0.41 \\
50 & 1.38 & 0.57 \\
\hline
\end{tabular}

(c) $\mathrm{NaSCN}$

\begin{tabular}{lcc}
\hline wt\% of Salt & \multicolumn{2}{c}{ Value of exponent “ $n$ " } \\
$\begin{array}{c}\text { Higher frequency } \\
\text { range }\end{array}$ & $\begin{array}{c}\text { Lower frequency } \\
\text { range }\end{array}$ \\
\hline 5 & 1.46 & 0.52 \\
10 & 1.44 & 0.63 \\
15 & 1.41 & 0.56 \\
20 & 1.46 & 0.54 \\
25 & 1.36 & 0.46 \\
30 & 1.35 & 0.30 \\
35 & 1.47 & 0.36 \\
40 & 1.40 & 0.48 \\
45 & 1.68 & 0.54 \\
50 & 1.48 & 0.25 \\
\hline
\end{tabular}

parameters follows the trend of conductivity variation with salt concentration as shown in Figure 1.

Superlinear power law is characterized by presence of a shallow to deep minima in dielectric loss spectra depending upon the strength of SLPL behavior. Hence, for a crosscheck
TABLE 4: Values of relaxation peak frequency in imaginary part of Modulus versus frequency curve.

\begin{tabular}{lccc}
\hline \multirow{2}{*}{ wt\% of Salt } & \multicolumn{3}{c}{ Peak frequency (Hz) in $\mathrm{M}^{\prime \prime}$} \\
\hline 5 & $\mathrm{NaSCN}$ & $\mathrm{NaI}$ & $\mathrm{NaClO}_{4}$ \\
10 & 1945000 & 1945000 & 2462000 \\
15 & 1213000 & 756200 & 1536000 \\
20 & 1536000 & 2462000 & 2462000 \\
25 & 1213000 & 1078000 & 1945000 \\
30 & 1213000 & 2462000 & 1213000 \\
35 & 2771000 & 1945000 & 2462000 \\
40 & 1078000 & 2462000 & 2462000 \\
45 & 1365000 & 3118000 & 1365000 \\
50 & 419100 & 2462000 & 2462000 \\
\hline
\end{tabular}

of the SLPL region, discussed in Section 3.2, dielectric loss variations with frequency have been studied. Figures 5(a) and 5(b) represent the variation of $\varepsilon^{\prime}, \varepsilon^{\prime \prime}$ with frequency for one salt $(\mathrm{NaI})$. These curves represent the typical polymer electrolyte type of nature. Curves in Figure 5(c) indicate towards presence of a shallow minimum at high frequency when plotted in extended view for sodium iodide. Similar curves are, also, found for other two systems. This confirms our conclusion regarding the ion dynamics discussed in Section 3.2.

The impedance data is further analyzed in terms of electrical modulus as depicted in Figures 6(a) and 6(b). Values of Electrical modulus have been calculated using following formulas:

$$
M^{\prime}=\frac{\varepsilon^{\prime}}{\left(\varepsilon^{\prime \prime 2}+\varepsilon^{\prime 2}\right)}, \quad M^{\prime \prime}=\frac{\varepsilon^{\prime \prime}}{\left(\varepsilon^{\left.\prime \prime^{2}+\varepsilon^{\prime 2}\right)}\right.}
$$

Relaxation peaks observed in $M^{\prime \prime}$ versus $\log \omega$ curves are summarized in Table 4. Peaks shift with salt concentration in the similar fashion as conductivity variation.

\section{Conclusion}

Potato starch-based electrolyte systems doped with sodium salts of three different anion, namely, $\mathrm{ClO}_{4}^{-}, \mathrm{I}^{-}$, and $\mathrm{SCN}^{-}$, have been successfully prepared. Anion size and conductivity follow an inverse trend indicating systems to be predominantly anionic conductor. Anion size has an inverse effect on number of charge carriers. All of the prepared materials have $t_{\text {ion }}>0.99$ confirming their electrolytic nature. Multiplet formation tendency of iodide ion affected the mobility trend. SLPL is observed in studied frequency range at room temperature. Anion size has affected the range of its dominance, which has been further confirmed by dielectric loss parameter variation with frequency. 


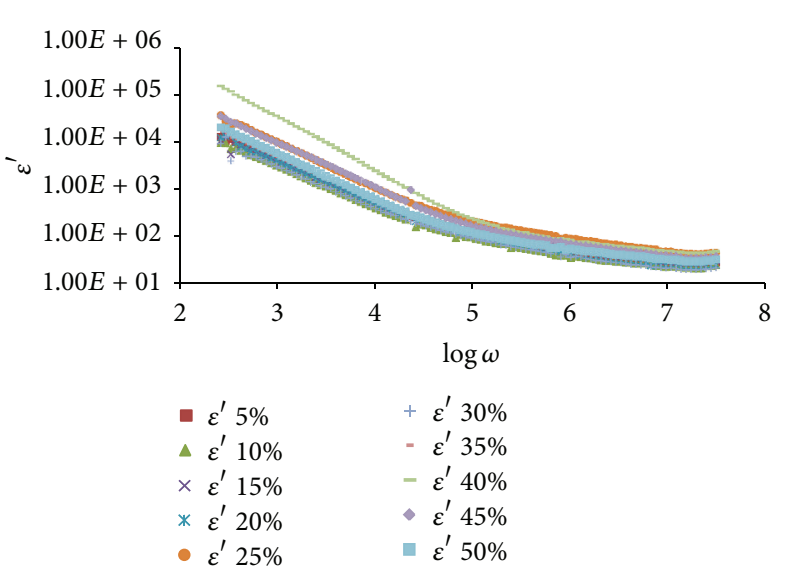

(a)

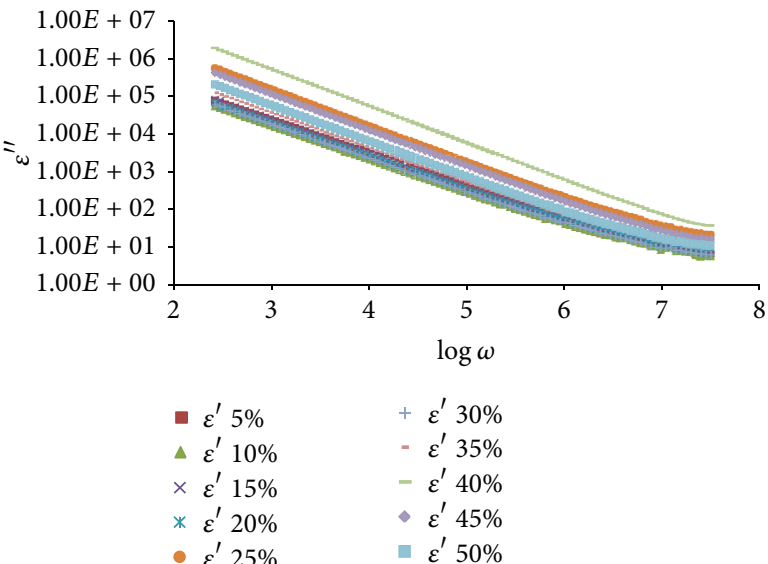

(b)

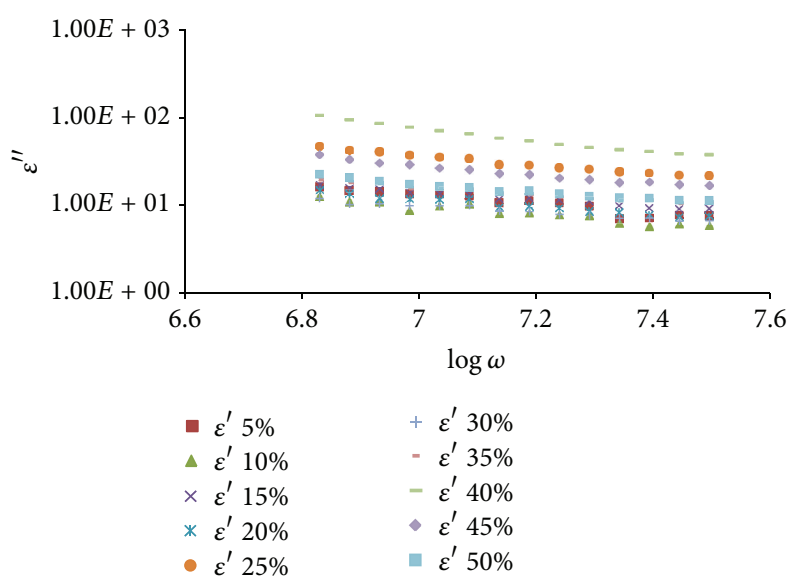

(c)

FIGURE 5: Variation of (a) real part and (b) imaginary part of dielectric parameter with frequency. (c) Extended view of (b) at higher frequency for NaI.

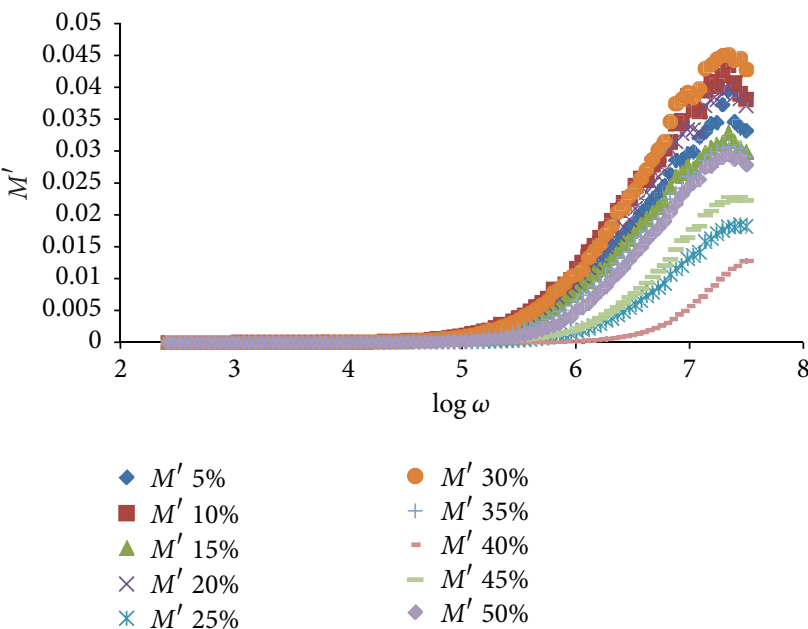

(a)

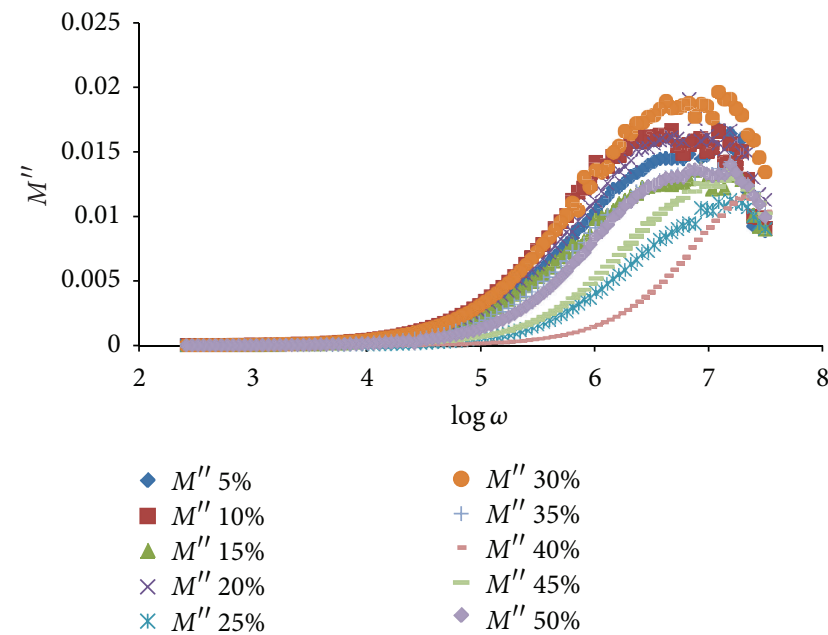

(b)

FIgURE 6: Variation of (a) real part (b) imaginary part of electric modulus variation with frequency for NaI. 


\section{Acknowledgments}

DST New Delhi is acknowledged for financial support to the project "Development of sodium ion conductingelectrochemical application" (DST reference no. SR/S2/ CMP0065/2007, dated 08/04/2008). Instruments procured in the project are used in the present work.

\section{References}

[1] M. B. Armand, J. M. Chabango, and M. Duclot, Second International Meeting on Solid Electrolytes, St. Andrews, UK, University of St. Andrews edition, 1978.

[2] T. Basu, M. M. Goswami, T. R. Middya, and S. Tarafdar, "Morphology and ion-conductivity of gelatin- $\mathrm{LiClO}_{4}$ films: fractional diffusion analysis," Journal of Physical Chemistry B, vol. 116, no. 36, pp. 11362-11369, 2012.

[3] R. Singh, B. Bhattacharya, N. A. Jadhav, S. Majmudar, and P. K. Singh, "Novel biopolymer gel electrolyte for dye-sensitized solar cell application," Carbohydrate Polymer, vol. 91, no. 2, pp. 682-685, 2012.

[4] V. L. Finkenstadt, "Natural polysaccharides as electroactive polymers," Applied Microbiology and Biotechnology, vol. 67, no. 6, pp. 735-745, 2005.

[5] V. L. Finkenstadt and J. L. Willett, "Electroactive materials composed of starch," Journal of Polymers and the Environment, vol. 12, no. 2, pp. 43-46, 2004.

[6] D. F. Vieira, C. O. Avellaneda, and A. Pawlicka, "Conductivity study of a gelatin-based polymer electrolyte," Electrochimica Acta, vol. 53, no. 4, pp. 1404-1408, 2007.

[7] R. G. F. Costa, C. O. Avellaneda, A. Pawlicka, S. Heusing, and M. A. Aegerter, "Optoelectrochemical characterization of electrochromic devices with starch based solid electrolytes," Molecular Crystals and Liquid Crystals, vol. 447, pp. 45-53, 2006.

[8] W. Ning, Z. Xingxiang, L. Haihui, and H. Benqiao, "1-Allyl3-methylimidazolium chloride plasticized-corn starch as solid biopolymer electrolytes," Carbohydrate Polymers, vol. 76, no. 3, pp. 482-484, 2009.

[9] T. Tiwari, N. Srivastava, and P. C. Srivastava, "Electrical transport study of potato starch-based electrolyte system," Ionics, vol. 17, no. 4, pp. 353-360, 2011.

[10] M. Kumar, T. Tiwari, and N. Srivastava, "Electrical transport behaviour of bio-polymer electrolyte system: potato starch + ammonium iodide," Carbohydrate Polymers, vol. 88, no. 1, pp. 54-60, 2012.

[11] A. K. Jonscher, "The "universal" dielectric response," Nature, vol. 267, no. 5613, pp. 673-679, 1977.

[12] A. K. Jonscher, The Universal Dielectric Response: A Review of Data Their New Interpretation, Chelsea Dielectrics Group, London, UK, 1978.

[13] D. P. Almond, G. K. Duncan, and A. R. West, "The determination of hopping rates and carrier concentrations in ionic conductors by a new analysis of ac conductivity," Solid State Ionics, vol. 8, no. 2, pp. 159-164, 1983.

[14] J. P. Tiwari and K. Shahi, "Ion dynamics in mechanochemically synthesized amorphous fast ionic conductor $\mathrm{Ag}_{2} \mathrm{~S}_{-} \mathrm{Sb}_{2} \mathrm{~S}_{3}$," Solid State Ionics, vol. 176, no. 13-14, pp. 1271-1280, 2005.

[15] S. Ke, H. Huang, S. Yu, and L. Zhou, "Crossover from a nearly constant loss to a superlinear power-law behavior in Mn-doped $\mathrm{Bi}\left(\mathrm{Mg}_{1 / 2} \mathrm{Ti}_{1 / 2}\right) \mathrm{O}_{3}-\mathrm{PbTiO}_{3}$ ferroelectrics," Journal of Applied Physics, vol. 107, no. 8, Article ID 084112, 4 pages, 2010.
[16] C. Cramer and M. Buscher, "Complete conductivity spectra of fast ion conducting silver iodide/silver selenate glasses," Solid State Ionics, vol. 105, no. 1-4, pp. 109-120, 1998.

[17] S. R. Elliott, "Frequency-dependent conductivity in ionically and electronically conducting amorphous solids," Solid State Ionics, vol. 70-71, no. 1, pp. 27-40, 1994.

[18] P. Lunkenheimer, T. Götzfried, R. Fichtl et al., "Apparent giant dielectric constants, dielectric relaxation, and ac-conductivity of hexagonal perovskites $\mathrm{La}_{1.2} \mathrm{Sr}_{2.7} \mathrm{BO}_{7.33}(\mathrm{~B}=\mathrm{Ru}, \mathrm{Ir})$," Journal of Solid State Chemistry, vol. 179, no. 12, pp. 3965-3973, 2006.

[19] S. S. Sekhon and S. Chandra, "Mixed cation effect in silver borate ion conducting glass," Journal of Materials Science, vol. 34, no. 12, pp. 2899-2902, 1999.

[20] J. Evans, C. A. Vincent, and P. G. Bruce, "Electrochemical measurement of transference numbers in polymer electrolytes," Polymer, vol. 28, no. 13, pp. 2324-2328, 1987.

[21] R. J. Klein, S. Zhang, S. Dou, B. H. Jones, R. H. Colby, and J. Runt, "Modeling electrode polarization in dielectric spectroscopy: ion mobility and mobile ion concentration of single-ion polymer electrolytes," Journal of Chemical Physics, vol. 124, no. 14, Article ID 144903, 8 pages, 2006.

[22] P. Lunkenheimer and A. Loidl, "Response of disordered matter to electromagnetic fields," Physical Review Letters, vol. 91, no. 20, Article ID 207601, 4 pages, 2003.

[23] A. K. Jonscher, Dielectric Relaxation in Solids, Chelsea Dielectrics Press, London, UK, 1983.

[24] I. Sakellis, "On the origin of time-temperature superposition in disordered solids," Applied Physics Letters, vol. 98, no. 7, Article ID 072904, 3 pages, 2011.

[25] B. Roling, C. Martiny, and S. Murugavel, "Ionic conduction in glass: new information on the interrelation between the "jonscher behavior" and the "nearly constant-loss behavior" from broadband conductivity spectra," Physical Review Letters, vol. 87, no. 8, Article ID 085901, 4 pages, 2001.

[26] J. P. Tiwari and K. Shahi, "Super-linear frequency dependence of ac conductivity of disordered $\mathrm{Ag}_{2} \mathrm{~S}_{-} \mathrm{Sb}_{2} \mathrm{~S}_{3}$ at cryogenic temperatures," Philosophical Magazine, vol. 87, no. 29, pp. 44754500, 2007.

[27] T. Tiwari, M. Kumar, N. Srivastava, and P. C. Srivastava, "Electrical transport study of potato starch-based electrolyte system-II," Materials Science and Engineering B, 2013. 

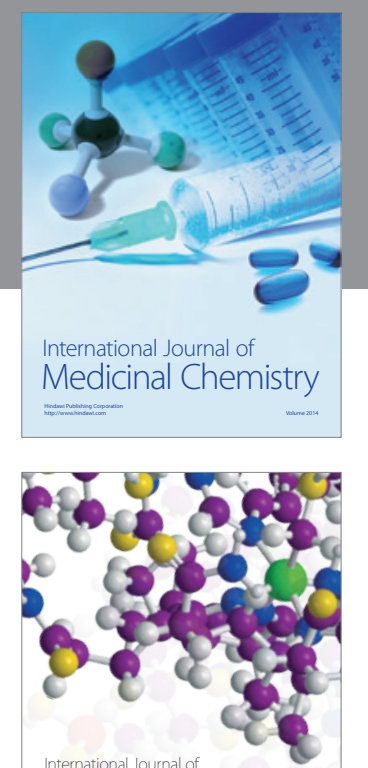

\section{Carbohydrate} Chemistry

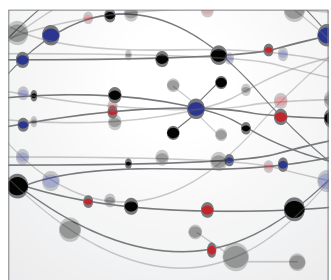

The Scientific World Journal
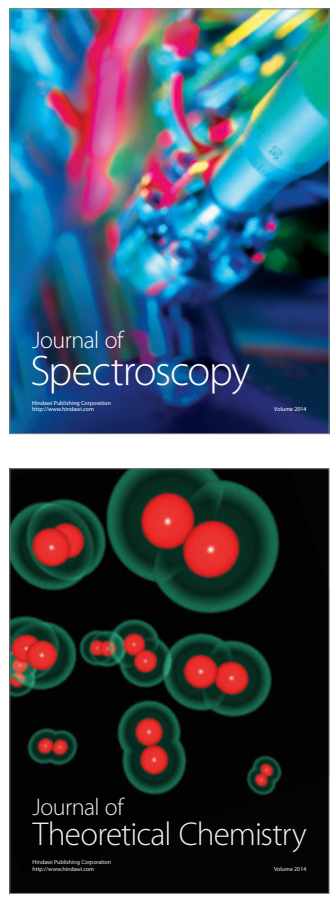
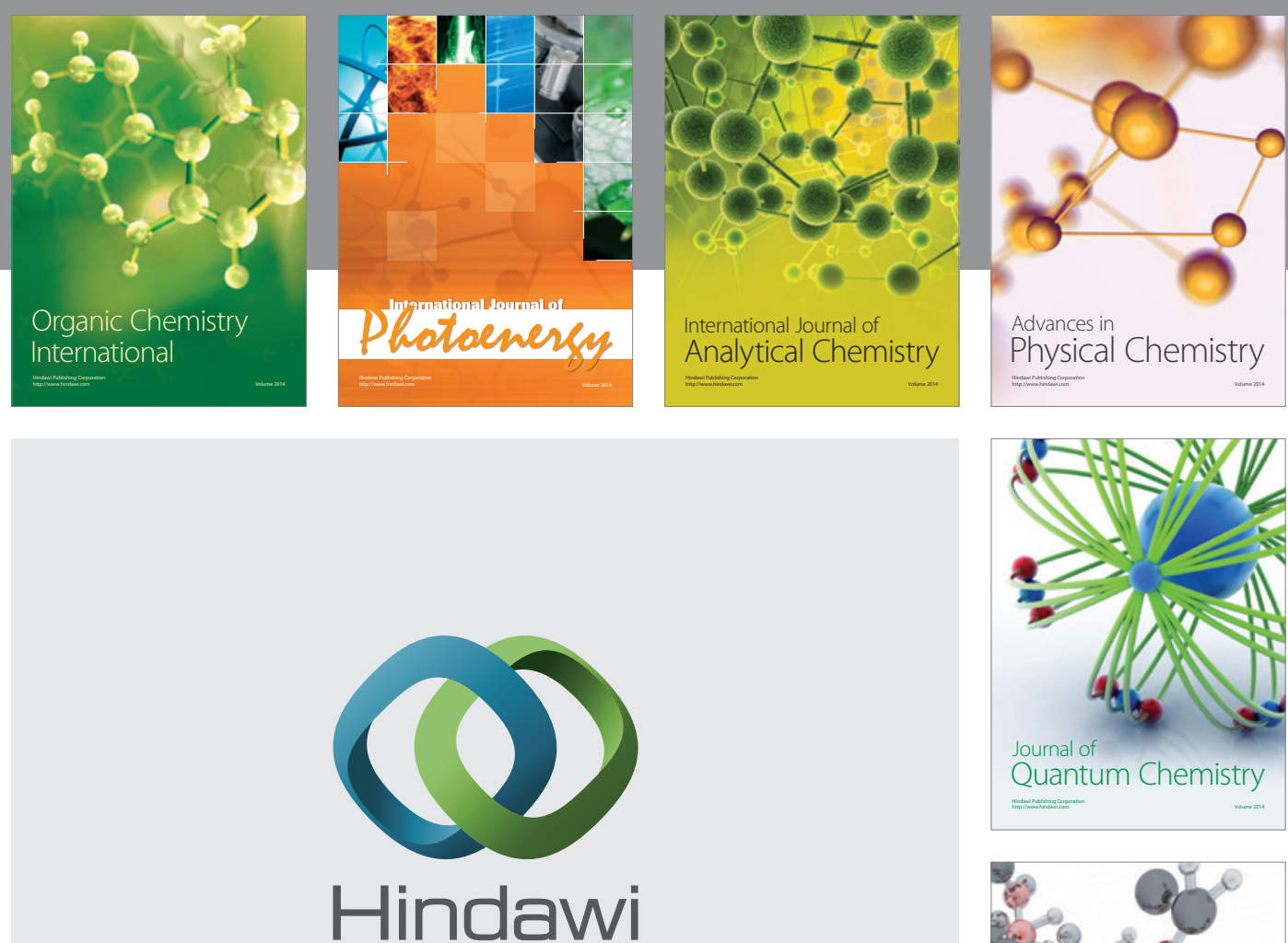

Submit your manuscripts at

http://www.hindawi.com

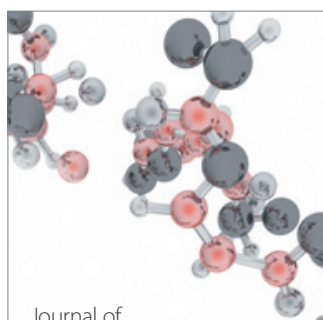

Analytical Methods

in Chemistry

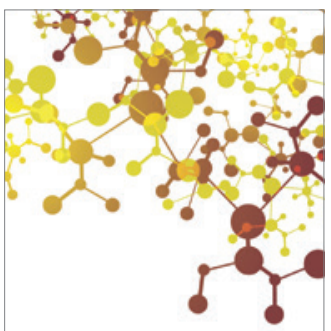

Journal of

Applied Chemistry

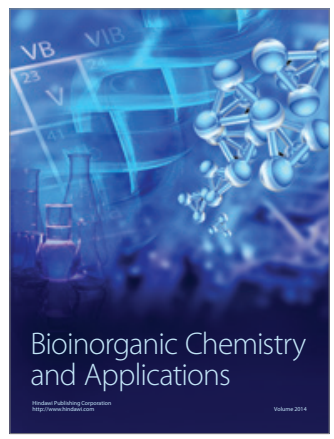

Inorganic Chemistry
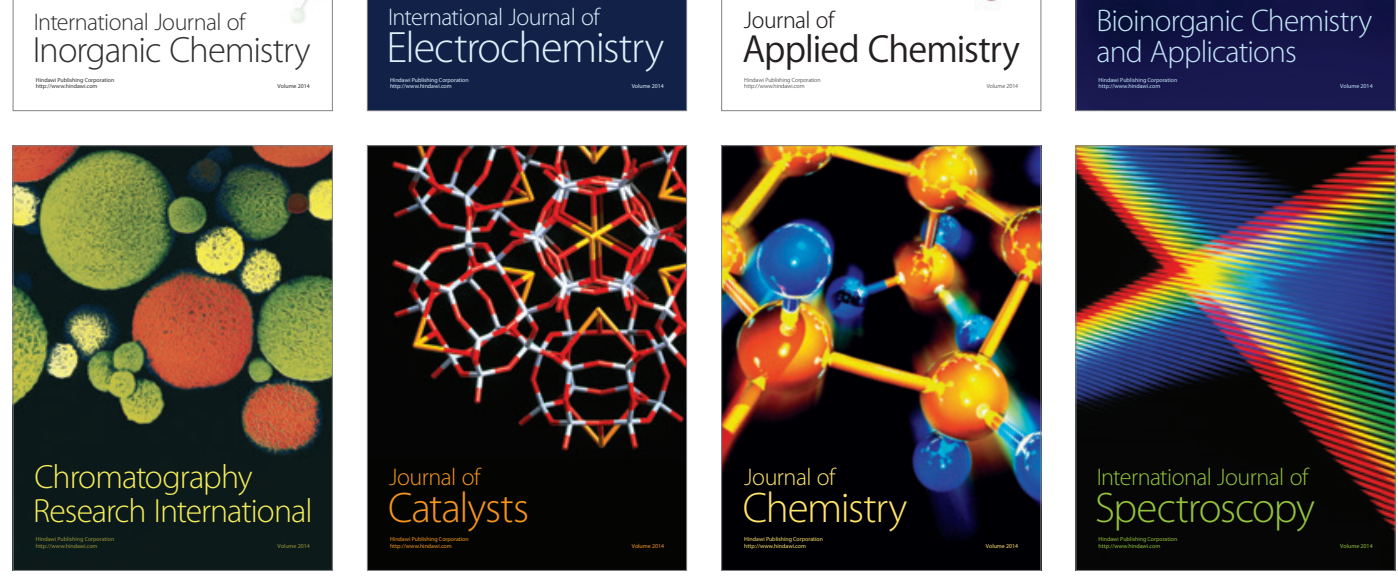